\section{Residual gain analysis using STWMULTR, a computer program designed to retrieve and punch residual scores}

\author{
CARL E. EDEBURN \\ South Dakota State University, Brookings, South Dakota 57006
}

One of the most difficult tasks in psycho-educational research investigation has been the measurement of change. When pre- and posttesting models have been implemented, the most prevalent application in most analyses has been the use of raw gain scores. Due to the inadequacies of this approach several different solutions, including residual gain analysis, have been proposed.

Residual Gain Analysis. Essentially, the residual gain method can be conceived as a partial correlation between the group membership variable and the residuals in the posttest data using the pretest as a predictor. Since change as expressed in a residual score is unrelated to original performance in a testretest design (Glass \& Stanley, 1970), it can be assumed that any changes as reflected in the residual scores can be more accurately attributed to the time of the study.

The residual gain analysis approach has been discussed by Dubois $(1957,1970)$ and Bakan (1970). Others (Buzzahora \& Williams, 1973; Edeburn \& Landry, 1974; Williams \& Maresh, 1972) have applied this technique in test-retest situations using the elementary school students' scores as elicited by various cognitive and affective measures.

The STWMULTR Program. One of the physical limitations of the residual gain application has been the amount of clerical time spent in extracting the residual scores for each subject from a typical regression printout and repunching them on appropriately identified cards. The present effort was aimed at overcoming this limitation.

To a common version of a stepwise multiple linear regression program originally adapted from the Scientific Subroutine Package (IBM, 1972), the present writer has added an optional feature which stores and then punches the residual scores for each subject on a new data card. This new program is identified in the South Dakota State University Computing Center as STWMULTR.

Input. Data cards containing the original pre- and posttest scores for each subject are submitted for regression analysis in the usual manner. The only restriction is that the first card for each subject in this original data set must include one to eight columns of alphanumeric ID.

Output. By using individual selection cards (pretest predicting posttest on each subscale) to determine the residuals and calling for the punch option, the researcher is able to obtain a new set of data cards containing up to eight columns of the original alphanumeric ID, and the residual gain scores for each subject. These scores are punched in fields of F 73, and there is room for 10 scores on each card. Should the research in question require more than 10 scores, the program will continue to punch on additional cards in the same format, retaining the ID for each additional card.

After obtaining the new cards, normal regression procedures can be easily implemented.

Availability. Interested users may contact the author for further details. Source decks will be made available for $\$ 3$. This includes the cost of postage. A program listing and documentation will be sent free of charge; however, postage would be appreciated.

\section{REFERENCES}

BAKAN, D. Analysis of covariance in training research. In P. H. Dubois and G. D. Mayo (Eds.), Research strategies for evaluation training. Chicago: Rand McNalley, 1970.

Buzzahora. R. C.. \& Williams, J. D. An empirical comparison of residual gain analysis and the analysis of covariance. Multiple Linear Regression Viewpoints, 1973, 4, 10-17.

Dunois. P. H. Multivariate correlational analysis. New York: Harper. 1957.

Dubois. P. H. Correlational analysis in training research. In P. H. Dubois and G. D. Mayo (Eds.). Research strategies for evaluation training. Chicago: Rand MeNalley. 1970.

Edeburn. C. E.. \& Landry, R. G. Self-concepts of students and a signiticant other. the teacher. Psychological Reports. 1974. 35. 505-506.

Glass, G. V.. \& Stanley, J. C. Statistical methods in education and psichology: Englewood Cliffs, N.J: Prentice-Hall, 1970.

IBM. Concepts and applications of regression analysis. (3rd ed.) White Plains. N.Y: Author, 1972.

Williams. J. D.. \& Maresh. R. T. A comparison of raw gain scores. residual gain scores, and the analysis of covariance with two modes of teaching reading. Multiple Linear Regression Viewpoints, 1972, 2, 2-16. 